\title{
Gonadectomy in Complete Androgen Insensitivity Syndrome: Why and When?
}

\author{
Ulla Döhnert ${ }^{\mathrm{a}} \quad$ Lutz Wünsch $^{\mathrm{b}}$ Olaf Hiort ${ }^{\mathrm{a}}$ \\ ${ }^{a}$ Division of Paediatric Endocrinology and Diabetes, Department of Paediatrics and Adolescent Medicine, and \\ ${ }^{b}$ Department of Paediatric Surgery, University of Lübeck, Lübeck, Germany
}

\section{Keywords}

Disorders of sex development - Hormone therapy .

Malignant germ cell tumors · Puberty - Tumor risk

\begin{abstract}
Prophylactic gonadectomy has been recommended in complete androgen insensitivity syndrome (CAIS) because of an increased risk for the development of malignant germ cell tumors in the intra-abdominal gonads. No reliable screening parameters are available to detect early (pre-)malignant changes. Because the tumor risk before puberty is very low, the timing of gonadectomy has been postponed to allow spontaneous puberty and involvement of the patients in important decisions affecting their body and health. Gonadectomy after puberty is still discussed controversially. There are difficulties in determining the absolute malignancy risk for individuals with CAIS, difficulties with hormone therapy, and lack of studies supporting different protocols. In contrast, endogenous hormone profiles show very specific features that influence bone health, psychosocial well-being, and many other aspects which still have to be investigated. For women with CAIS who wish to keep their gonads, we propose a biannual screening program which has to be evaluated in a prospective multi-center trial.
\end{abstract}

(c) 2017 S. Karger AG, Basel
Complete androgen insensitivity syndrome (CAIS) is characterized by a complete external female genital appearance despite a 46,XY karyotype and unrestricted testicular development with functioning Leydig cells [Hughes et al., 2012]. The underlying condition is a peripheral resistance towards all androgenic steroids due to a mutation of the androgen receptor. This leads to a very specific endocrine environment with slightly elevated $\mathrm{LH}$ levels and FSH, testosterone, and estradiol values in the male reference range despite pubertal feminization [Doehnert et al., 2015].

The current debate on the prophylactic gonadectomy versus the saving of the testes is inflamed by several points. As reviewed by Cools et al. [this issue], an increased risk for testicular germ cell tumors (GCT) has been demonstrated. However, support groups and patients are fighting for keeping their gonads based on their personal experience of unphysiological hormone replacement after gonadectomy. Furthermore, they condemn the violation of bodily integrity through gonadectomy. Therefore, this debate has to consider the medical arguments and the ethical implications of a life-changing procedure in a patient cohort with a rare medical condition.

\section{KARGER}

E-Mail karger@karger.com

www.karger.com/sxd
Prof. Dr. Olaf Hiort

Sektion für Exp. Pädiatrische Endokrinologie und Diabetes

Klinik für Kinder- und Jugendmedizin, Universität zu Lübeck

Ratzeburger Allee 160, DE-23538 Lübeck (Germany)

E-Mail olaf.hiort@uksh.de 


\section{Current Arguments against Gonadectomy}

The essential argument for gonadectomy in CAIS is the prevention of malignant degeneration of the intraabdominal or inguinal gonads. As explained by Cools et al. [this issue], there is an increased incidence of germ cell neoplasia in situ (GCNIS) in the gonads of people with both CAIS and PAIS (partial androgen insensitivity syndrome) compared to the general male population [Manuel et al., 1976; Rutgers and Scully, 1991; Cools et al., 2016]. The exact determination of the incidence of (pre-)malignant gonadal tumors in CAIS has, however, been impeded by early gonadectomy, lack of confirmation of diagnosis by sequencing of the $A R$ gene, unknown numbers of undiagnosed healthy women with CAIS, and further study and publication bias [Deans et al., 2012].

Progression of GCNIS to invasive GCT is assumed to be obligatory in the general population. Differences in pathophysiology leading to a potentially lower risk in CAIS have been explained [Kaprova-Pleskacova et al., 2013; Cools et al., 2016]. Supporting this hypothesis, most of the unsuspected lesions found at gonadectomy are histologically classified as GCNIS [Cheikhelard et al., 2008; Nakhal et al., 2013; Cools et al., this issue]. Reported malignant tumors comprise mostly seminomas and few others like malignant Leydig cell tumor and mixed GCT [Sakai et al., 2000; Iwamoto et al., 2005; Shahidi and Robia, 2007; Herman et al., 2010; Tsubamoto et al., 2013]. Stage 1 GCT can be managed by surgical removal and surveillance alone, and prognosis is very good with survival rates close to $100 \%$ [Ehrlich et al., 2015].

\section{Current Arguments for Gonadectomy}

Gonads can be localized and investigated by modern imaging techniques. In the first line, this is best achieved by ultrasound (US). In CAIS, the testes-like features like size and shape as well as the low echogenicity and vascular structure are often readily detected, whereas müllerian structures are more difficult to identify. As already discussed by Cools et al. [this issue], there are nonspecific markers of malignant changes as microlithiasis in combination with heterogeneous echogenicity which have only been evaluated for gonads without DSD [Elzinga-Tinke et al., 2010]. Further investigation by magnetic resonance imaging (MRI) can reveal localization of intra-abdominal gonads and genital duct anatomy. There have not been any studies comparing US and MRI, and correlations of early invasive GCT in CAIS are unknown in both techniques [Nakhal et al., 2013]. If a gonad cannot be detected or a gonadal tumor is suspected, laparoscopy is needed for detailed assessment [Wünsch and Buchholz, 2014]. GCNIS or early invasive GCT can only be diagnosed by a gonadal biopsy, which will result in gonadectomy [Wünsch, 2012].

\section{The Dilemma of Gonadectomy}

If gonadectomy is considered, an informed consent must be obtained. The surgeons' responsibility is to assess the individual balance of risks and benefits and to explain this to the patient. The lack of evidence and individual patient-related factors such as insight, the general perception of tumor risk, the availability of qualified health care, and the body constitution have to be considered. Thus, decision making about gonadectomy should be considered as a time-consuming process, and the patient should have an active time-intensive role. The postponement of eventual gonadectomy into adult age is a major advance. Not only does it allow spontaneous puberty to occur, more importantly it permits informed and authoritative decision-making by the patient.

The occurrence of an inguinal hernia during childhood should not be taken as an indication for early gonadectomy. The hernia should be repaired and the gonad fixed to the internal inguinal ring or repositioned into the abdomen. The risk of gonadectomy includes the risks of general anesthesia and those of laparoscopy. Both risks are very low, and laparoscopic gonadectomy can be done as an outpatient procedure. Bilateral gonadectomy takes approximately $30-45 \mathrm{~min}$. Laparoscopy also allows biopsies or gonadopexy, and, moreover, gonadectomy leaves almost no visible scar.

If gonadectomy is postponed, many new questions arise. How does endocrine function develop in adulthood, and when does it decline? How many germ cell tumors will occur, and how will they affect the lives of the patients?

After gonadectomy, continuous and long-term hormone therapy is necessary to achieve induction of puberty and maintenance of sexual function, psychosocial well-being, and bone health [Bertelloni et al., 2011]. So far, there have not been any studies reported that examine different hormonal medications, their dosage, and routes of administration necessary to obtain these aims. In addition, compliance with hormone therapy is widely variable, depending on health-related education, medical care, and well-being.
172
Sex Dev 2017;11:171-174 DOI: $10.1159 / 000478082$
Döhnert/Wünsch/Hiort 
Patients and support groups have explicitly pointed out the aspects of bodily harm exerted by gonadectomy and problems with unphysiological hormone replacement therapy [Cools et al., 2016]. Still the impact of gonadectomy and hormone therapy has only been addressed in few studies on long-term outcome [Wisniewski et al., 2000; Minto et al., 2003]. Most of the studies included none or only few participants with intact gonads so that results could not be compared either. Existing studies show an impairment of sexual function in women with CAIS [Minto et al., 2003; Köhler et al., 2012] and a higher degree of psychosocial distress [D'Alberton et al., 2015], while female identity and behavior and general quality of life do not differ significantly from other women [Wisniewski et al., 2000; Hines et al., 2003; Minto et al., 2003].

Studies of small populations of women with CAIS reveal an elevated risk of developing reduced bone mineral density under hormone replacement, mostly estrogen therapy, compared with endogenous hormone production in intact gonads [Bertelloni et al., 2010; Meriggiola et al., 2015]. Further studies have to examine the clinical relevance of reduced bone mineral density and possibilities of adopting hormone therapy accordingly. Bone health therefore represents an important issue regarding longterm morbidity after gonadectomy. The influence of gonadectomy on other metabolic parameters affecting cardiovascular morbidity might be relevant as well [Dati et al., 2009].

Recently, we have examined the very specific endocrine profiles of women with CAIS [Doehnert et al., 2015]. A conclusion towards "irregular" or "abnormal" cannot be made in this condition as the usual male/female pattern is lacking and therefore a reference population does not exist. Presumably, further steroids and hormones secreted in the testes contribute to a complex milieu influencing body functions. Among others, testicular INSL3 [Ferlin et al., 2013] has been demonstrated to affect bone mineralization as outlined by Bertelloni et al. [this issue].

\section{Proposal for a Screening}

At this time, it is mostly agreed that gonadectomy in CAIS children prior to puberty is not warranted on a prophylactic basis. These children should undergo their usual pubertal development with endogenous hormone synthesis and should be informed about their condition in due course.

With respect to a potentially increased risk of malignancy after puberty, gonadectomy at this stage should still be the first-line recommendation. However, difficulties of determining the malignancy risk as well as problems of hormone therapy after gonadectomy must be discussed with the patients. For women who wish to keep their gonads, we propose a regular (bi-)annual screening program comprising gonadal imaging by US or MRT, depending on the size and localisation of the gonad, determination of tumor markers (alpha-fetoprotein, betaHCG, LDH, and optionally PLAP in non-smokers), and endocrine evaluation (LH, FSH, testosterone, and inhibin B). Again, it has to be stressed that no specific and sensitive parameters exist for early detection of (pre-)malignant changes in the gonads so that in other high-risk populations (e.g., for ovarian cancer) early gonadectomy is still recommended. Accordingly, laparoscopy with gonadal biopsy and possibly gonadectomy will be necessary in any woman with CAIS and suspicious findings in the screening. Such a study protocol should be investigated in a prospective multi-center trial.

\section{References}

Bertelloni S, Baroncelli GI, Mora S: Bone health in disorders of sex differentiation. Sex Dev 4: 270-284 (2010).

Bertelloni S, Dati E, Baroncelli GI, Hiort O: Hormonal management of complete androgen insensitivity syndrome from adolescence onward. Horm Res Paediatr 76:428-433 (2011).

Cheikhelard A, Morel Y, Thibaud E, Lortat-Jacob $S$, Jaubert F, et al: Long-term follow-up and comparison between genotype and phenotype in 29 cases of complete androgen insensitivity syndrome. J Urol 180:1496-1501 (2008).

Gonadectomy in CAIS
Cools M, Simmonds M, Elford S, Gorter J, Ahmed SF, et al: Response to the Council of Europe Human Rights Commissioner's Issue Paper on Human Rights and Intersex People. Eur Urol 70:407-099 (2016).

D’Alberton F, Assante MT, Foresti M, Balsamo A, Bertelloni S, et al: Quality of life and psychological adjustment of women living with $46, \mathrm{XY}$ differences of sex development. J Sex Med 12:1440-1449 (2015).

Dati E, Baroncelli GI, Mora S, Russo G, Baldinotti F, et al: Body composition and metabolic profile in women with complete androgen insensitivity syndrome. Sex Dev 3:188-193 (2009).
Deans R, Creighton SM, Liao LM, Conway GS: Timing of gonadectomy in adult women with complete androgen insensitivity syndrome (CAIS): patient preferences and clinical evidence. Clin Endocrinol (Oxf) 76:894-898 (2012).

Doehnert U, Bertelloni S, Werner R, Dati E, Hiort $\mathrm{O}$ : Characteristic features of reproductive hormone profiles in late adolescent and adult females with complete androgen insensitivity syndrome. Sex Dev 9:69-74 (2015).

Ehrlich Y, Margel D, Lubin MA, Baniel J: Advances in the treatment of testicular cancer. Transl Androl Urol 4:381-390 (2015). 
Elzinga-Tinke JE, Sirre ME, Looijenga LH, van Casteren N, Wildhagen MF, Dohle GR: The predictive value of testicular ultrasound abnormalities for carcinoma in situ of the testis in men at risk for testicular cancer. Int J Androl 33:597-603 (2010).

Ferlin A, Selice R, Carraro U, Foresta C: Testicular function and bone metabolism - beyond testosterone. Nature Rev Endocrinol 9:548-554 (2013).

Herman M, Wernicke GA, Yan U, Nori D, Prashar B: Pure seminoma in the setting of androgen insensitivity syndrome treated with surgical resection and para-aortic radiation: a case report and review of the literature. J Cancer Res Ther 6:318-320 (2010).

Hines M, Ahmed SF, Hughes IA: Psychological outcomes and gender-related development in complete androgen insensitivity syndrome. Arch Sex Behav 32:93-101 (2003).

Hughes IA, Davies JD, Bunch TI, Pasterski V, Mastroyannopoulou K, MacDougall J: Androgen insensitivity syndrome. Lancet 380:14191428 (2012).

Iwamoto I, Yanazume S, Fujino T, Yoshioka T, Douchi T: Leydig cell tumor in an elderly patient with complete androgen insensitivity symdrome. Gynecol Oncol 96:870-872 (2005).
Kaprova-Pleskacova J, Stoop H, Brüggenwirth $\mathrm{H}$, Cools M, Wolffenbuttel KP, et al: Complete androgen insensitivity syndrome: factors influencing gonadal histology including germ cell pathology. Mod Pathol 27:721-730 (2013).

Köhler B, Kleinemeier E, Lux A, Hiort O, Grüters $A$, et al: Satisfaction with genital surgery and sexual life of adults with XY disorders of sex development: results from the German clinical evaluation study. J Clin Endocrinol Metab 97:577-588 (2012).

Manuel M, Katayama PK, Jones Jr HW: The age of occurrence of gonadal tumors in intersex patients with a Y chromosome. Am J Obstet Gynecol 124:293-300 (1976).

Meriggiola MC, Dati E, Berra M, Bombardini C, Baldinotti $\mathrm{F}$, et al: Bone mineral density in women with complete androgen insensitivity syndrome: effects of gonadal removal and sex steroids substitutive therapy. Oral Communication, 5th I-DSD Symposium, 11th-13th June, Ghent, Belgium; Abstracts book (2015).

Minto CL, Liao KL, Conway GS, Creighton SM: Sexual function in women with complete androgen insensitivity syndrome. Fertil Steril 80:157-164 (2003).

Nakhal RS, Hall-Craggs M, Freeman A, Kirkham A, Conway GS, et al: Evaluation of retained testes of adolescent girls and women with complete androgen insensitivity syndrome. Radiology 268:153-160 (2013).
Rutgers JL, Scully RE: The androgen insensitivity syndrome (testicular feminization): a clinicopathologic study of 43 cases. Int J Gynecol Pathol 10:126-144 (1991).

Sakai N, Yamada T, Asao T, Baba M, Yoshida M, Murayama T: Bilateral testicular tumors in androgen insensitivity syndrome. Int J Urol 7: 390-392 (2000).

Shahidi H, Robia M: Bilateral germ cell tumors and androgen insensitivity syndrome. J Clin Oncol 25:4686-4688 (2007).

Tsubamoto H, Yada Y, Sakata K, Kondoh N, Sawai H: A large seminoma occurring 20 years after diagnosis of complete androgen insensitivity syndrome: a case report. Gynecol Oncol Case Rep 5:16-18 (2013).

Wisniewski AB, Migeon CJ, Meyer-Bahlburg HFL, Gearhart JP, Berkovitz GD, et al: Complete androgen insensitivity syndrome: longterm medical, surgical, and psychosexual outcome. J Clin Endocrinol Metab 85:26642668(2000).

Wünsch L: Checklist for the structural description of the deep phenotype in disorders of sexual development. Int J Endocrinol 2012: 816365 (2012)

Wünsch L, Buchholz M: Imaging, endoscopy and diagnostic surgery, in Hiort O, Ahmed SF (eds): Understanding Differences and Disorders of Sex Development (DSD), vol 27, pp 76-86 (Karger, Basel 2014). 